Int. J. Electrochem. Sci., 15 (2020) 4032 - 4055

\title{
Inhibition Corrosion Effect of Extract from Basella rubra on Carbon Steel in HCl Solution
}

\author{
Cuijie Shi ${ }^{1,2}$, XiaoPing Song ${ }^{1}$, Ying Kan ${ }^{1}$, Yu Fan ${ }^{2, *}$, Xiaowei Song ${ }^{1}$, Yinglan Zhang ${ }^{3,4}$, \\ Zhengdong Zhang ${ }^{1, *}$ \\ ${ }^{1}$ National Institute of Metrology, Beijing 100029, China \\ ${ }^{2}$ College of Chemical Engineering and Environment, China University of Petroleum-Beijing, Beijing \\ 102249, China \\ ${ }^{3}$ Leibniz-Institut für Polymerforschung Dresden, Germany \\ ${ }^{4}$ Technische Universität Dresden, Germany \\ *E-mail: zhangzhengdong@ nim.ac.cn (Z.Zhang); fanyu@cup.edu.cn (Yu Fan)
}

doi: $10.20964 / 2020.05 .57$

Received: 9 January 2020 / Accepted: 17 february 2020 / Published: 10 April 2020

The inhibition behavior of fruit extract of Basella rubra on corrosion of carbon steel in $1 \mathrm{~mol} \mathrm{~L}^{-1} \mathrm{HCl}$ solution was studied by weight loss and electrochemical methods. The adsorption of extract obeys Langmuir adsorption isotherm. Electrochemical results reveal that the inhibitor acts as mix type inhibitor but cathodically predominant. The separated substituents can also inhibit the corrosion of carbon steel in $\mathrm{HCl}$ solution efficiently. SEM and XPS results demonstrate that the protective layer formed by extract molecules can effectively inhibit corrosion process at metal surface.

Keywords: Carbon steel; Corrosion inhibitor; Weight loss; EIS; HCl solution

\section{FULL TEXT}

(C) 2020 The Authors. Published by ESG (www.electrochemsci.org). This article is an open access article distributed under the terms and conditions of the Creative Commons Attribution license (http://creativecommons.org/licenses/by/4.0/). 